\title{
Article \\ Can an Intermediate Rate of Nitrogen Inversion Affect Drug Efficacy?
}

\author{
Raphael R. Steimbach ${ }^{1,2}$, Gergely Tihanyi ${ }^{1,2}$, , Magalie N. E. Géraldy ${ }^{1,3}{ }^{\text {, Alicja Wzorek }}{ }^{4}\left(\right.$, Aubry K. Miller ${ }^{1,5}(\mathbb{D}$ \\ and Karel D. Klika ${ }^{1, *}$ \\ 1 Cancer Drug Development, German Cancer Research Center (DKFZ), Im Neuenheimer Feld 280, \\ D-69120 Heidelberg, Germany; r.steimbach@dkfz.de (R.R.S.); gergely.tihanyi@fmi.ch (G.T.); \\ geraldy.mag@hotmail.fr (M.N.E.G.); aubry.miller@dkfz.de (A.K.M.) \\ 2 Biosciences Faculty, University of Heidelberg, D-69120 Heidelberg, Germany \\ 3 Bayer AG, Friedrich-Ebert Straße 217/333, D-42117 Wuppertal, Germany \\ 4 Institute of Chemistry, Jan Kochanowski University in Kielce, Uniwersytecka 7, 25-406 Kielce, Poland; \\ alicja.wzorek@ujk.edu.pl \\ 5 German Cancer Consortium (DKTK), D-69120 Heidelberg, Germany \\ * Correspondence: k.klika@dkfz.de; Tel.: +49-6221-42-4515
}

Citation: Steimbach, R.R.;

Tihanyi, G.; Géraldy, M.N.E.; Wzorek, A.; Miller, A.K.; Klika, K.D Can an Intermediate Rate of Nitrogen Inversion Affect Drug Efficacy? Symmetry 2021, 13, 1753. https://doi.org/10.3390/sym13091753

Academic Editor: George

Papageorgiou

Received: 11 June 2021

Accepted: 11 August 2021

Published: 20 September 2021

Publisher's Note: MDPI stays neutral with regard to jurisdictional claims in published maps and institutional affiliations.

Copyright: (c) 2021 by the authors. Licensee MDPI, Basel, Switzerland. This article is an open access article distributed under the terms and conditions of the Creative Commons Attribution (CC BY) license (https:/ / creativecommons.org/licenses/by/ $4.0 /)$.
Abstract: Nitrogen-inversion rates and diffusion coefficients were measured using ${ }^{1} \mathrm{H}$ NMR for 14 drug-like molecules. The slow nitrogen-inversion rates interconverting the enantiomers of these molecules lay within a postulated intermediate range in terms of their ability to bind to proteins bounded by diffusion constraints, potentially affecting the availability, hence efficacy, of these compounds if they were utilized as drugs. The postulated intermediate range is based on a capturevolume concept, whereby the nitrogen inversion during the time a ligand takes to pass through a volume surrounding the protein binding site, as calculated by the diffusion rate, determines if it will influence ligand binding to the protein. In the systems examined here, the measured nitrogeninversion rates and the times required to traverse the capture volume differed by a few orders of magnitude. Potentially more consequential are intermediate nitrogen-inversion rates in epimeric cases-since the energies of the interconverting species are unequal, a heavy bias against the eutomer might occur. The implications of an intermediate nitrogen-inversion rate are significant for in silico drug design, drug efficacy, molecular modeling of drug-protein binding, pharmacokinetics, drug enantiomer evaluation, etc. Due consideration of the process should thus be taken into account for drug development directions and in vitro evaluation.

Keywords: nitrogen inversion; diffusion; rate determination; molecular chirality; protein binding

\section{Introduction}

Since the early 1990s, regulatory agencies have required extensive and increasing stereochemical information on chiral drugs [1,2] concerning their uptake, disposition, pharmacokinetics, pharmacodynamics, stability, racemization, epimerization, etc. Consequently, the configurational stability of drugs susceptible to stereochemical interconversion is of great interest. While the question of drug racemization or epimerization in vitro and in vivo has long been, and continues to be, at the forefront of drug development and preparation $[3,4]$, this appears not to have been specifically considered in the case of labile structures where stereochemical interconversion, either in vitro or in vivo, can occur at much faster rates relative to the usually considered rates.

The inversion of the configuration in tetrahedral $\mathrm{sp}^{3}$-hybridized nitrogen (nitrogen inversion) has been known since 1934 when the inversion of $\mathrm{NH}_{3}$ was first detected [5] by microwave spectroscopy. The process has been well-studied [6] and the rates of nitrogen inversion vary greatly from quite slow, e.g., invertomers have been prepared that could be physically separated [7], to exceedingly fast [6,8,9], e.g., $\mathrm{NH}_{3}$ inverts at a rate of 
$2.4 \times 10^{10} \mathrm{~s}^{-1}$ [6]. Influences on the nitrogen-inversion rate include $[6,10]$ steric factors, (hyper)conjugation, electronegativity, electron lone pair repulsions, angle strain, intramolecular interactions, and metal complexation. For a nitrogen atom with four different ligands and thereby constituting a stereocenter, nitrogen inversion results in a change of configuration from $R(S)$ to $S(R)$ (Figure 1). The species can either be a neutral tertiary amine with the electron lone pair constituting a ligand or a quaternary ammonium ion whereby nitrogen inversion is only feasible when one of the ligands is a proton.

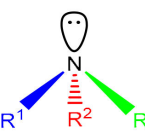

$S$

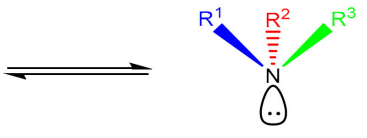

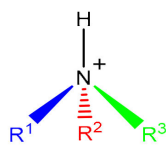

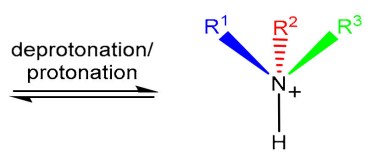

$R$

Figure 1. The enantiomeric interconversion due to nitrogen inversion for a neutral tertiary amine with the electron lone pair constituting a ligand and deprotonation/protonation for a quaternary ammonium ion.

Substituents attached to a ring nitrogen are normally considered labile in terms of their ring orientation due to nitrogen inversion. With other stereocenters in the molecule, epimers result, even with an overwhelmingly predominant orientation [11-13]. For cases where the participating epimers possess similar energies, the two interconverting species can be "frozen out" by low-temperature NMR measurements if the nitrogen-inversion rate is sufficiently slow $[12,13]$. In fused-bicyclic systems with a bridgehead nitrogen, equilibria between cis and trans structures can occur due to nitrogen inversion and the two interconverting structures can similarly be "frozen out" by low-temperature NMR measurements $[14,15]$. However, since the hybridization, and thus the geometry, of a nitrogen atom is relatively fluid [13-16], a nitrogen atom adopting near-planar geometry renders the notion of inversion redundant. Cases, though, are generally limited to fusedbicyclic structures possessing either significant geometrical constraints or considerable steric hindrance $[11,13-16]$. Nitrogen inversion retardation by complexation to a metal as part of a chiral complex can yield diastereotopic methyls in a $-\mathrm{N}\left(\mathrm{CH}_{3}\right)_{2}$ fragment or, for appropriately substituted nitrogen atoms, distinct signals for epimers at reduced temperatures. Even $-20^{\circ} \mathrm{C}$ can be sufficient for such observations [10].

While the problem of stereoisomeric interconversion has long been considered pharmacologically relevant, rapid stereochemical interconversion-with species non-separable in terms of manufacture, storage, and patient uptake-does not seem to have been given due attention, as typified by invertomers arising from nitrogen inversion. Since tertiary amines are present [17], including pharmaceuticals, in nearly $30 \%$ of bioactive molecules, nitrogen inversion, as well as rotation about the nitrogen-carbon bond, should be an interesting process in medicinal chemistry in order to explain possible interactions with biological targets. Given that the selection of a conformer(s) from a dynamic equilibrium [18-26], and hence the biological activity of the compound under scrutiny, is dependent on conformational interchange, the case for nitrogen inversion is clear. This is of particular consideration for interconverting epimers, perhaps even of greater concern than enantiomeric interconversion, as the energies of the interconverting species are typically unequal with the possibility of heavy bias against the eutomer. Thus, for drugs or drug candidates containing nitrogen atom stereocenters, it is likely that the nitrogen-based enantiomers/epimers have different binding energies to their biological targets. That is, the target proteins might be stereoselective for particular nitrogen-based enantiomers/epimers of the drug. However, while drug stereoisomer interconversion and protein interactions with stereoisomers have been addressed in systems with carbon atom stereocenters [3,4], and consideration also given to conformational interconversion [2,20-26], analogous consideration with respect to nitrogen atom stereocenters does not appear to have been addressed. Presumably this is because nitrogen-inversion rates are assumed to be so rapid [6] that their effects can be considered 
inconsequential and can therefore be safely ignored. Though it is well known that nitrogen inversion can be slow $[6,7,10]$, it seems the effect of an intermediate nitrogen-inversion rate on drug-protein interactions has been neglected. This deficiency needs to be addressed as it can have serious consequences and implications in terms of the effective eutomer concentration within an organism, the amount of drug actually binding to the active site, drug efficacy, and potency discrepancies between in vitro and in vivo observations, as well as for the assumptions that are made in docking and other computational modeling studies.

During synthetic work to develop new amine-containing inhibitors of histone deacetylase 10 (HDAC10i) [27,28], we synthesized several amines that revealed unexpected features in their ${ }^{1} \mathrm{H}$ NMR spectra. Depending on the conditions, methylene protons were sometimes chemically inequivalent or the signals were very broad due to a slow nitrogen-inversion rate. We therefore considered whether a slow rate of nitrogen inversion might have pharmacological significance by postulating what was a relevant rate and relating this to a postulated capture-volume concept. Both nitrogen-inversion rates and diffusion coefficients were measured using ${ }^{1} \mathrm{H}$ NMR. In pharmaceutics, diffusion-based NMR methodology is well established $[29,30]$, while previous studies [8,9] of nitrogen inversion have used the interconversion of diastereotopic methylene protons and selective saturation transfer [31] to measure the nitrogen-inversion rates. In all, 14 drug-like molecules, including an epimeric example, were examined. As a result of this study, we believe that the effect of an intermediate nitrogen-inversion rate has been overlooked with respect to drug-protein interactions. The problem of an intermediate nitrogen-inversion rate is likely to be general and not restricted to this particular set of compounds as there is nothing peculiar about the compounds examined here and hence concerns extend to other compounds with similar nitrogen-inversion rates.

\section{Results and Discussion}

\subsection{Prelude}

As mentioned, we observed some unexpected features in the ${ }^{1} \mathrm{H}$ NMR spectra of several synthesized amines. As an example, the hydroxamic acid $\mathbf{1} \cdot \mathbf{H C l}$ (Figure 2) exhibited chemically inequivalent methylene protons in its ${ }^{1} \mathrm{H}$ NMR spectrum. Depending on the conditions, the signals could be distinct and sharp (Figure 3 ) or otherwise extremely broad due to a faster exchange rate. These observations were evident to varying degrees in various deuterated solvents including DMSO, methanol, and water for both protonated and non-protonated $\mathbf{1}$ as well as other amines examined in this work (vide infra), though the effects were much less pronounced for non-protonated cases. That the methylene protons in $\mathbf{1}$ were exchanging spins, when they were observed as distinct signals, was confirmed by 2D EXSY NMR spectra. In the absence of other causes, these observations are consistent with nitrogen inversion being slow on the NMR timescale for this NMR system.<smiles>CN(CCCC(=O)NO)CCC(=O)Nc1ccccc1</smiles>

Figure 2. Structure of the drug-like hydroxamic acid $\mathbf{1 .}$

We wished to confirm our supposition of a slow nitrogen-inversion rate but needed to circumvent issues associated with the multiple functional groups present within $\mathbf{1}$ which could potentially lead to confusion regarding the actual process in operation. For example, restricted rotation about the amide and/or hydroxamic acid bonds. Therefore, we first examined a simple system lacking other functional groups to exclude the effects due to other interactions to verify that the observations were indeed associated with nitrogen inversion. To this end, $N$-ethyl- $N$-methylbenzylamine (2, Figure 4) was examined wherein similar observations to $\mathbf{1}$ for protonated $\mathbf{2}$ were again present in its ${ }^{1} \mathrm{H}$ NMR spectrum. 
Furthermore, the chemically inequivalent methylene protons could be rendered chemically equivalent on the NMR timescale by raising the temperature (Figure 5).

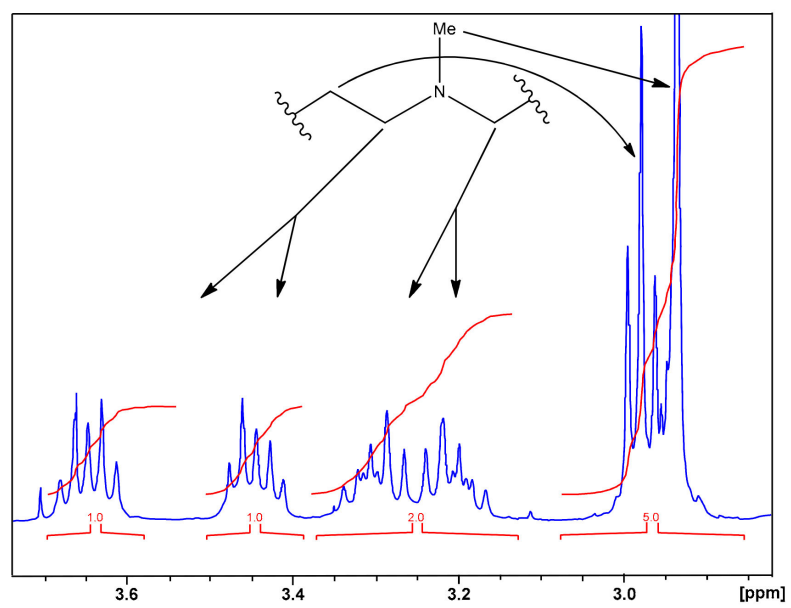

Figure 3. The ${ }^{1} \mathrm{H}$ NMR spectrum of a concentrated sample of hydroxamic acid $\mathbf{1} \cdot \mathbf{H C l}$ in $\mathrm{D}_{2} \mathrm{O}$ showing the region containing the signals for two pairs of chemically inequivalent methylene protons due to a nitrogen-inversion rate that is sufficiently retarded such that the spin exchanges for the two pairs of methylene proton signals are in the slow-exchange regime for this NMR system. The partial structure of $\mathbf{1}$ with the assignment of the diastereotopic protons is indicated.<smiles>[CH][C@@H](C)[NH+](C)c1ccccc1</smiles>

2

Figure 4. Structure of protonated 2 explicitly showing the diastereotopic methylene proton pairs of the benzyl and ethyl groups.

\subsection{The Capture-Volume Concept}

Clearly the nitrogen-inversion rates under the applied conditions for compounds $\mathbf{1}$ and $\mathbf{2}$ are much slower than might be normally anticipated, and leads to the question of whether the nitrogen-inversion rate, if sufficiently slow, can affect protein-binding interactions. To answer this question, we introduce the concept of the capture volume. To understand this concept, consider the following two extreme scenarios and the resulting implications for a drug undergoing an interconversion process with the assumed constraint that only the favored state of a drug molecule binds to the protein, while the disfavored state does not:

1. The rate of the interconversion process is infinitely fast relative to the molecule's motional diffusion so that binding of the drug to the active site in the protein occurs irrespective of the state of the drug molecule as the favored state is quickly adopted from the disfavored state before the drug molecule diffuses away from the active site. The result is that there is no effect at all on the action of the drug due to the rapid interconversion process.

2. The rate of the interconversion process is infinitely slow, or even does not occur at all prior to clearance, and the result is that the dosage of the drug is effectively half that dispensed in the case, say, of rapid enantiomeric interconversion. An obvious example would be a chiral drug that is configurationally stable and is dispensed as a racemate. 


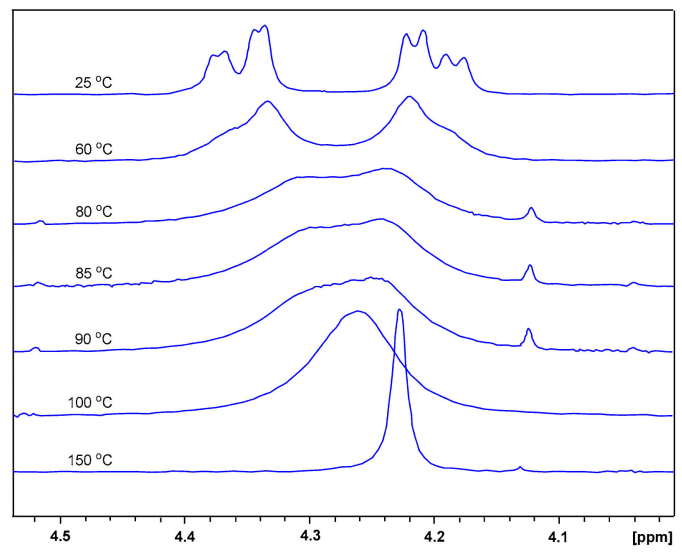

Figure 5. The ${ }^{1} \mathrm{H}$ NMR signals for the methylene proton signals of the benzyl group of $\mathbf{2} \cdot \mathbf{H C l}$ in DMSO- $d_{6}$ measured in the range $25-150{ }^{\circ} \mathrm{C}$ displaying the change from chemically inequivalent signals at $25{ }^{\circ} \mathrm{C}$ to a singlet at $150{ }^{\circ} \mathrm{C}$ comprising two chemically equivalent protons. At $25{ }^{\circ} \mathrm{C}$, in addition to the geminal coupling, there is also a vicinal coupling to the labile $\mathrm{NH}$ proton that is lost at elevated temperatures due to rapid chemical exchange. Signal coalescence is considered to occur at $90^{\circ} \mathrm{C}$. Note, the appearing/disappearing/re-appearing signal of an impurity at $4.12 \mathrm{ppm}$ is illusory, each spectrum has been acquired with varying quality of $B_{0}$ homogeneity ("shim") and number of scans, processed with varying amounts of line broadening, and scaled independently to yield a clear presentation of the dynamics occurring for the signals of interest.

These two aspects - the probability of bringing ligand and protein together and the probability of attaining the specific orientation of the ligand during the formation of a complex-are recognized as the first two steps constituting the overall process of molecular association [25]. But between these extreme scenarios, intermediate interconversion rates can still potentially affect drug availability, hence efficacy, depending on organism clearance rates. Thus consider a third scenario:

3. The rate of the interconversion process is intermediate. Thus, while a drug molecule in the disfavored state will not bind to the protein when it encounters the active site and will diffuse away, later, after it has converted to the favored state, it is then able to bind to the protein when it again encounters it. The result is that while all of the drug is, in principle, available to bind to the protein, the availability of the drug is restricted as it is present at an effectively lower concentration even though it might be interconverting at a reasonable rate. The question is, what constitutes a reasonable rate?

To assess if an interconversion rate conforms to the intermediate range criteria, the following conceptual system is considered. Extending out from the binding site of a protein is a volume (Figure 6) - for the sake of simplicity the shape of the volume is taken to approximate a hemisphere, but see the caption for Figure 6 for a more realistic appraisaland if a drug molecule is present in this volume, it will bind to the protein with a high degree of probability if it has the right configuration or conformation. This volume is defined as the capture volume. Obviously, the size of the capture volume will be dependent on both the nature of the protein and the drug involved, but for the purposes here it will be arbitrarily declared as having a radius of $1000 \AA$. Thus, depending on whether the molecule retains the state it had when it entered the capture volume, if the favored state of a drug molecule enters this space, it will bind to the protein, while the disfavored state will not bind to the protein. Thus, the question of what constitutes a fast, intermediate, or slow nitrogen-inversion rate simplifies to whether the disfavored state of a drug molecule is likely to convert to the favored state, or conversely, during its passage through the capture volume. The time taken for the drug molecule to traverse $2000 \AA$, i.e., by heading directly towards the active site and then reflecting away (but see the caption for Figure 6 for a more realistic appraisal), is easily ascertained by measuring the diffusion rate of the 
molecule by NMR. Similarly, the nitrogen-inversion rate can also be measured by NMR. A comparison of these measured processes then indicates which range the system belongs to: fast, intermediate, or slow. Though we have arbitrarily defined the size of the capture volume, since there is a broad range of nitrogen-inversion rates, there are likely to be a suite of nitrogen-inversion rates and capture volume sizes that meet the criteria for which the postulate is valid.

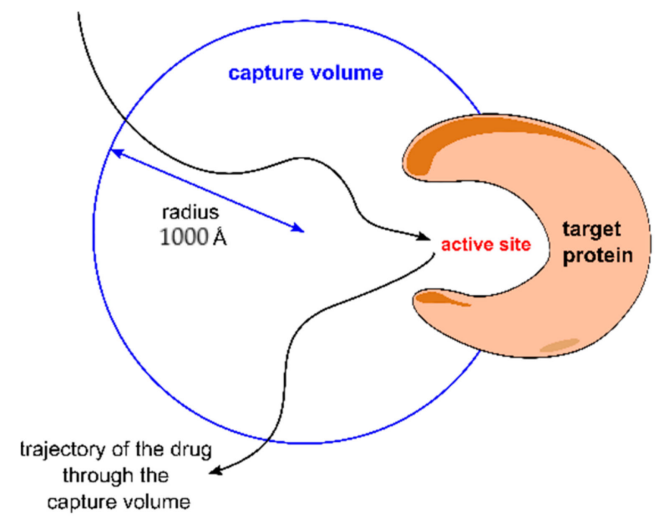

Figure 6. Cartoon depiction of the capture-volume concept. The capture volume may approximate a hemisphere but would presumably likely deviate one way or the other from such a shape close to the protein surface, hence it is not depicted as an exact hemisphere and the spatial relationships are exaggerated in the figure. With a radius of $1000 \AA$, a linear passage from the edge of the hemisphere directly to the center of the sphere and then linearly exiting by a similar route would result in a path length of $2000 \AA$. A real trajectory, however, would unlikely be linear and thus the actual path length, coupled with the actual location of the binding site away from the center of the sphere, would be expected to be somewhat longer than $2000 \AA$, but for the sake of simplicity is simply taken as $2000 \AA$.

\subsection{Detailed Examination of 2 by ${ }^{1} H N M R$}

As stated above, since intra- and intermolecular hydrogen bonding-based interactions are possible in many drug compounds due to multiple functional groups and potentially complicate the issue, we first examined in detail the simple compound 2 to circumvent these issues and confirm that nitrogen inversion can have an intermediate rate independent of such interactions. In this work, the complication of intra- or intermolecular hydrogen bonding-based interactions which may also cause the chemical inequivalence of methylene protons was similarly eliminated by the use of $\mathrm{D}_{2} \mathrm{O}$ or $\mathrm{CD}_{3} \mathrm{OD}$ as the solvent and/or dilute solutions.

Examinations of non-protonated 2 in both DMSO- $d_{6}$ and $\mathrm{D}_{2} \mathrm{O}$ provided ${ }^{1} \mathrm{H}$ NMR spectra in which the methylene proton pairs of the benzyl and ethyl groups appeared to be chemically equivalent, indicating nitrogen inversion to be fast on the NMR timescale under these conditions. Though some signal broadening might be present, even at $4{ }^{\circ} \mathrm{C}$ in $\mathrm{D}_{2} \mathrm{O}$ the nitrogen-inversion rate was still too fast to measure by NMR in the approach taken here. However, in the ${ }^{1} \mathrm{H}$ NMR spectrum of $\mathbf{2} \cdot \mathbf{H C l}$ in $\mathrm{CD}_{3} \mathrm{OD}$, the chemical inequivalence of the two methylene protons in both pairs from the benzyl (Figure 5) and ethyl groups was clear. From the measured diffusion coefficient of $8.53 \times 10^{-10} \mathrm{~m}^{2} \mathrm{~s}^{-1}$ at $25^{\circ} \mathrm{C}$ (Table 1 , Entry 1), the time required for a molecule of 2 to traverse a distance of $2000 \AA$ is $0.023 \mathrm{~ms}$. The selective saturation transfer experiments yielded a nitrogen-inversion rate of $2.33 \mathrm{~s}^{-1}$ at $25^{\circ} \mathrm{C}$, i.e., $429 \mathrm{~ms}$ is the required time for nitrogen inversion. Since the required time for inversion of the nitrogen atom is very much slower than the time it takes for the molecule to traverse the $2000 \AA$ Af the capture volume, clearly the nitrogen-inversion rate is in the postulated intermediate range, and thus could potentially affect any biological process that 2 , or any bioactive amine with a similar nitrogen-inversion rate, might be involved in if these rates are maintained under biological conditions. In $\mathrm{D}_{2} \mathrm{O}$ solution, however, the nitrogen inversion of protonated $\mathbf{2}$ was too fast to measure by NMR in the approach taken 
here and the signals of the methylene protons of both the benzyl and ethyl groups were ostensibly chemically equivalent, though both signals were broadened due to exchange since the system was not immeasurably far above coalescence. Diffusion did slow, as expected, to yield a diffusion coefficient of $5.12 \times 10^{-10} \mathrm{~m}^{2} \mathrm{~s}^{-1}$ at $25^{\circ} \mathrm{C}$ (Table 1, Entry 2). In phosphate-buffered saline (PBS), the nitrogen-inversion rate was fast at $37^{\circ} \mathrm{C}$, but at $4{ }^{\circ} \mathrm{C}$ the methylene protons of the ethyl group were just at coalescence, while the benzyl group methylene protons were just slightly above coalescence.

Table 1. Nitrogen-inversion rates and diffusion coefficients, $D$, for amines 1-4, 10-12, 14, and 15.

\begin{tabular}{|c|c|c|c|c|c|c|c|}
\hline Entry & Compd & Conc., mM & $\mathrm{pH}$ & Solvent & Temp., ${ }^{\circ} \mathrm{C}$ & Inv. Rate, $\mathrm{s}^{-1}$ & $D \times 10^{-10}, \mathrm{~m}^{2} \mathrm{~s}^{-1}$ \\
\hline 1 & $2 \cdot \mathrm{HCl}$ & 19.8 & - & $\mathrm{CD}_{3} \mathrm{OD}$ & 25 & $\begin{array}{c}2.33,0.25^{\mathrm{a}} \\
\left(T_{\mathrm{C}}=90^{\circ} \mathrm{C}\right)\end{array}$ & 8.53 \\
\hline 2 & $2 \cdot \mathrm{HCl}$ & 19.8 & 6 & $\mathrm{D}_{2} \mathrm{O}$ & 25 & - & 5.12 \\
\hline 3 & 1. TFA & 64.4 & 8 & $\mathrm{D}_{2} \mathrm{O}$ & 25 & 35.47 & 3.51 \\
\hline 4 & $1 \cdot$ TFA & unknown & 3 & $\mathrm{D}_{2} \mathrm{O}$ & 25 & 3.60 & 3.51 \\
\hline 5 & $3 \cdot$ TFA & $\begin{array}{l}\text { unknown, } \\
\text { sat. soln. }\end{array}$ & 3 & $\mathrm{D}_{2} \mathrm{O}$ & 25 & $\begin{array}{c}6.86,8.9^{\mathrm{a}} \\
\left(T_{\mathrm{C}}=45^{\circ} \mathrm{C}\right)\end{array}$ & 3.20 \\
\hline 6 & $4 \cdot$ TFA & 25.7 & 3 & $\mathrm{D}_{2} \mathrm{O}$ & 25 & 1.43 & 3.26 \\
\hline 7 & $14 \cdot \mathrm{HCl}$ & 69.9 & 3.5 & $\mathrm{D}_{2} \mathrm{O}$ & 25 & 1.24 & 3.81 \\
\hline 8 & 11 & 156.2 & 4 & $\mathrm{D}_{2} \mathrm{O}$ & 25 & 1.50 & 3.23 \\
\hline 9 & $14 \cdot \mathrm{HCl}$ & 69.9 & 3.5 & $\mathrm{D}_{2} \mathrm{O}$ & 37 & 5.32 & 5.40 \\
\hline 10 & $14 \cdot \mathrm{HCl}$ & 69.9 & 6 & $\mathrm{D}_{2} \mathrm{O}$ & 25 & $30-70^{b}$ & 3.79 \\
\hline 11 & 10 & 133.7 & 3 & $\mathrm{D}_{2} \mathrm{O}$ & 25 & 5.46 & 3.45 \\
\hline 12 & 12 & 107.8 & 3 & $\mathrm{D}_{2} \mathrm{O}$ & 25 & 1.35 & 3.70 \\
\hline 13 & 10 & 133.7 & 3 & $\mathrm{D}_{2} \mathrm{O}$ & 37 & 13.96 & 4.91 \\
\hline 14 & $15 \cdot \mathrm{HCl}$ & 20.0 & 7.5 & $\mathrm{D}_{2} \mathrm{O}$ & 25 & 1.19 & 4.47 \\
\hline
\end{tabular}

a The activation energy barrier, $\Delta G^{\ddagger}$, was calculated using the equation $\Delta G^{\ddagger}=4.575 \times 10^{-3} \times T_{\mathrm{c}} \times\left[9.972+\log _{10}\left(T_{\mathrm{c}} / \Delta v\right)\right]$ where $T_{\mathrm{c}}$ is the coalescence temperature and $\Delta v$ is the difference in Hz between the signals in the slow-exchange NMR regime. From $\Delta G^{\ddagger}$, the rate at $25^{\circ} \mathrm{C}$ was calculated using the Eyring Equation. ${ }^{\mathrm{b}}$ Estimated.

To confirm that the chemical inequivalence of the methylene protons was due to an intermediate rate of nitrogen inversion, a series of spectra for a sample of $2 \cdot \mathbf{H C l}$ at a concentration of $3.37 \mathrm{mM}$ in DMSO- $d_{6}$ were acquired at elevated temperatures (Figure 5). The progression from $25^{\circ} \mathrm{C}$ to $150^{\circ} \mathrm{C}$ revealed coalescence of the benzyl and ethyl methylene protons-at $150{ }^{\circ} \mathrm{C}$ a clear singlet was obtained in the case of the benzyl protons and a quartet in the case of the ethyl methylene protons. While the coalescence point of the ethyl methylene protons was obscured by the water signal, coalescence of the benzyl protons was observed to occur at $\sim 90^{\circ} \mathrm{C}$, and from a separation of $60 \mathrm{~Hz}$ at $25^{\circ} \mathrm{C}$, this equates to an activation energy of $\sim 18 \mathrm{kcal} \mathrm{mol}^{-1}$ for nitrogen inversion under these conditions and a calculated rate of $0.25 \mathrm{~s}^{-1}$ at $25^{\circ} \mathrm{C}$ (Table 1, Entry 1). The disparity to the rate measured by selective saturation transfer could be due to changes in the sample conditions, e.g., $\mathrm{pH}$ changes.

The effect of concentration was also examined from a comparison of $\mathbf{2} \cdot \mathbf{H C l}$ in $\mathrm{D}_{2} \mathrm{O}$ at concentrations of $19.8 \mathrm{mM}$ and $79.1 \mathrm{mM}$ with the higher concentration showing significantly greater exchange-induced line broadening. At very dilute concentrations, below $2 \mathrm{~mm}$ concentration in DMSO- $d_{6}$, any changes due to rate were insignificant, and even a sample of $16.2 \mathrm{mM}$ concentration was very comparable to the more dilute samples.

\subsection{Hydroxamic Acids $\mathbf{1}$ and $\mathbf{3}-\mathbf{1 4}$}

We next examined compounds that were more drug-like, consisting of a series of hydroxamic acids $\mathbf{1}$ and 3-9 (Figure 7). Included in the examination was compound $\mathbf{1 0}$ (an isomer of $\mathbf{1}$ with the substituents of the amide group switched) as well as some corresponding and homologous methyl esters 11-14. In general, it was found that the nitrogeninversion rate was dependent on the analyte concentration and the $\mathrm{pH}$ to the extent that the rate could easily be too fast to be measureable by NMR. Thus, for this set of compounds, most rate measurements were performed at low $\mathrm{pH}$. Conditions more closely resembling a 
biological state (e.g., PBS and $37^{\circ} \mathrm{C}$ ) were also attempted, but often the use of PBS accelerated the nitrogen-inversion rate to the point that the chemical inequivalence for methylene protons was lost (i.e., the signals coalesced), thus precluding measurement of the nitrogeninversion rate by NMR in the approach taken here. It should be noted that only fairly small increases in the nitrogen-inversion rate are required to lose the chemical inequivalence for methylene protons since the signals resonate so closely at the field strengths available in this work. As expected, with a rise in temperature, both the nitrogen-inversion rate and diffusion increased. But these changes are ineffectual to the premise at hand given that there are a few orders of magnitude difference between the time required to traverse the capture volume and the nitrogen-inversion rate. Hence the doubling or quadrupling of the nitrogen-inversion rate and the $\sim 40 \%$ increase in the diffusion coefficient (Table 1) are inconsequential. Thus an elevated temperature to match a biological state was not imperative and therefore the majority of the measurements were meaningfully conducted at $25^{\circ} \mathrm{C}$.
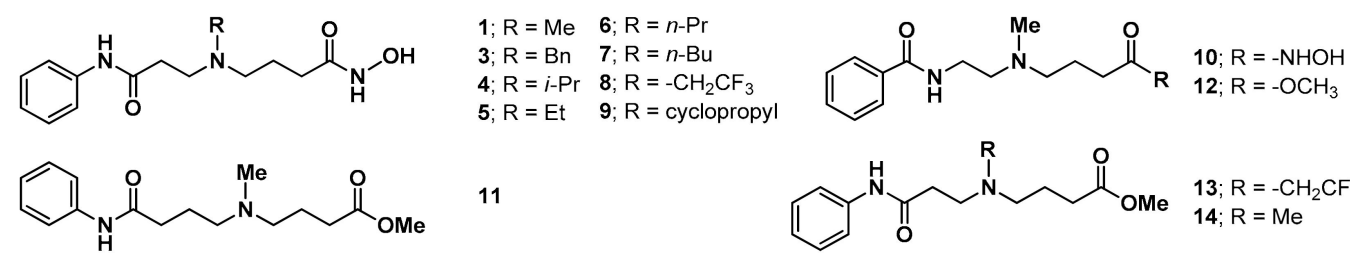

11

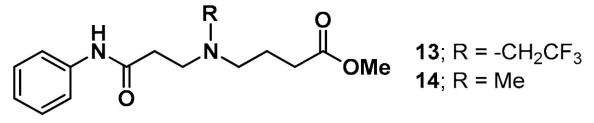

Figure 7. Structures of the set of drug-like molecules 1 and 3-14.

For 1-TFA, the parent compound in the series, the nitrogen-inversion rate in $\mathrm{D}_{2} \mathrm{O}$ was generally too fast to measure by NMR in the approach taken here. Sometimes, though, the rate was sufficiently slow to observe chemically inequivalent, albeit broad, proton signals, especially for the methylene pair $\alpha$ to the amine nitrogen atom of the ethylene segment as they have the largest signal separation in the slow-exchange NMR regime. With the inclusion of PBS, the rate was very fast, even for the TFA salt. In DMSO- $d_{6}$, the rate for the free base was variable, and probably also the content of water was another variable factor influencing the rate. However, the rate could be sufficiently slowed for either the $\mathrm{HCl}$ or TFA salt in DMSO- $d_{6}$ to observe chemically inequivalent protons. In both DMSO- $d_{6}$ and $\mathrm{D}_{2} \mathrm{O}$, higher concentrations were normally required to observe chemically inequivalent signals. In $\mathrm{D}_{2} \mathrm{O}$ at $25{ }^{\circ} \mathrm{C}$, a diffusion coefficient of $3.51 \times 10^{-10} \mathrm{~m}^{2} \mathrm{~s}^{-1}$ in $\mathrm{D}_{2} \mathrm{O}$ at $25{ }^{\circ} \mathrm{C}$ was measured (Table 1, Entry 3), thus the time required to traverse a distance of $2000 \AA$ is $0.057 \mathrm{~ms}$. For a solution of pH 8 (Table 1, Entry 3), a nitrogen-inversion rate of $35.47 \mathrm{~s}^{-1}$ was measured at $25^{\circ} \mathrm{C}$, i.e., $28 \mathrm{~ms}$ is the required time for nitrogen inversion. Lowering the $\mathrm{pH}$ to 3 (Table 1, Entry 4) provided very sharp signals and chemical inequivalence for both pairs of methylene protons $\alpha$ to the amine nitrogen atom. For the reduced rate of $3.60 \mathrm{~s}^{-1}$ at $\mathrm{pH} 3$, the time required for nitrogen inversion is $278 \mathrm{~ms}$. In either case, the inversion time for the nitrogen atom is very much slower than the time it takes for the molecule to traverse the $2000 \AA$ of the capture volume and clearly the nitrogen-inversion rate is in the postulated intermediate range. Thus, potentially, this could affect the binding of $\mathbf{1}$ to the protein target, HDAC10, if these rates are constrained to a similar scale under biological conditions.

For benzyl derivative 3.TFA in acidic $\mathrm{D}_{2} \mathrm{O}$, much better agreement was found in this instance between the rate determined by selective irradiation, $6.86 \mathrm{~s}^{-1}$, and the rate calculated from the coalescence temperature, $8.9 \mathrm{~s}^{-1}$ (Table 1, Entry 5). Measurements were made using the methylene protons $\beta$ to the amine nitrogen atom of the propylene segment as they were the only methylene pair that were chemically inequivalent. In this instance, the coalescence temperature, $45^{\circ} \mathrm{C}$, was much closer to the temperature used for the selective irradiation measurements, $25^{\circ} \mathrm{C}$. For TFA salt 3.TFA in $\mathrm{D}_{2} \mathrm{O}$ without acidification, and also in $\mathrm{CD}_{3} \mathrm{OD}$, the nitrogen-inversion rate was too fast to measure by NMR in the approach taken here, while in DMSO- $d_{6}$, though the rate was slower, the pertinent signals were still above coalescence and were extremely broad. For the free base 3 in all three 
solvents, the nitrogen-inversion rate was too fast to measure. By comparison, for isopropyl derivative $4 \cdot$ TFA in acidic $\mathrm{D}_{2} \mathrm{O}$ at $25^{\circ} \mathrm{C}$, signals were sharp and a nitrogen-inversion rate of $1.43 \mathrm{~s}^{-1}$ (Table 1, Entry 6) was measured. Almost identical diffusion coefficients, 3.20 and $3.26 \times 10^{-10} \mathrm{~m}^{2} \mathrm{~s}^{-1}$ were measured for 3.TFA and 4.TFA, respectively, in acidic $\mathrm{D}_{2} \mathrm{O}$ at $25^{\circ} \mathrm{C}$.

For ethyl derivative 5.TFA, the nitrogen-inversion rate in $\mathrm{D}_{2} \mathrm{O}$, even after lowering the $\mathrm{pH}$ to 3 , was fast and the signals remained sharp. The proton pairs of the methylenes along the backbone $\alpha$ to the amine nitrogen atom of the ethylene segment, $\alpha$ to the amine nitrogen atom of the propylene segment, and $\beta$ to the amine nitrogen atom of the propylene segment were all chemically equivalent, but interestingly exhibited strong effects due to magnetic inequivalence (Figure 8). It should be noted that chemically equivalent protons of a geminal pair in an ethylene or longer segment are always magnetically inequivalent, though generally any effect on the appearance of the multiplet due to magnetic inequivalence often goes unnoticed since the difference between ${ }^{3} J_{\mathrm{A}}$ and ${ }^{3} J_{\mathrm{A}^{\prime}}$ is, in most instances, sufficiently small as a consequence of near uniformly populated conformational space providing near equal vicinal couplings through averaging. The result is that the magnetic inequivalence of methylene protons in ethylene segments is generally masked by the linewidth of the signals in practice due to the typical acquisition and processing parameters used for acquiring and presenting ${ }^{1} \mathrm{H}$ NMR spectra. Though slow nitrogen inversion could compound the effects of magnetic inequivalence, it is not possible to disentangle nitrogen inversion from other processes affecting the couplings, such as conformational re-distribution, e.g., changing the temperature or the protonation state since both will affect the conformational distribution as well as the nitrogen-inversion rate. Moreover, the chemical shifts need to remain equivalent since the precept of magnetic inequivalence disappears with the appearance of chemical inequivalence, and since it is not possible for slow nitrogen inversion to affect the couplings without also affecting the chemical shifts, such a situation is considered most unlikely. As magnetic inequivalence is accentuated by an uptake of a preferred conformation(s), increasing the temperature will diminish any strong magnetic inequivalence effects observed in multiplets to provide multiplets more resembling first-order ones by making the vicinal couplings closer in value by way of averaging, and in the case of 5.TFA, only a rise in $20-30{ }^{\circ} \mathrm{C}$ was required for the linewidths to nearly obscure the effects of magnetic inequivalence (Figures S6-S8).

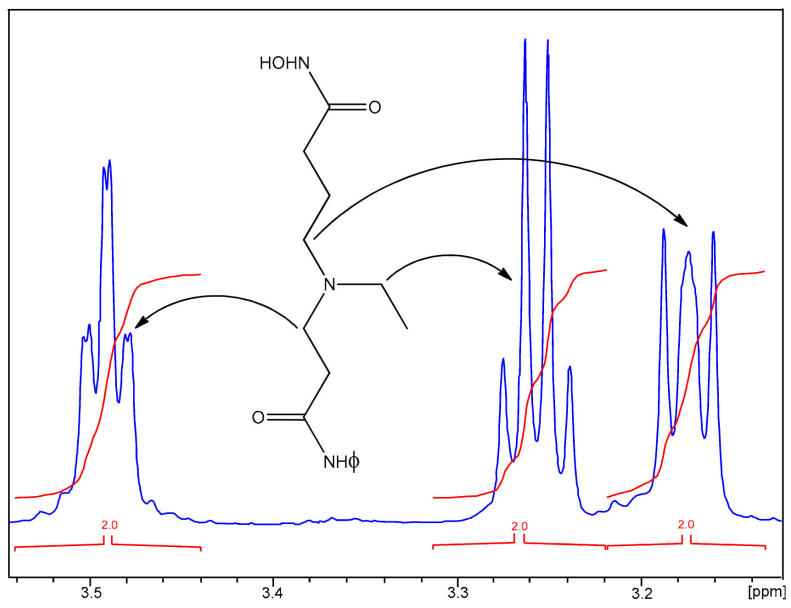

Figure 8. The region of the ${ }^{1} \mathrm{H}$ NMR spectrum of 5.TFA (in $\mathrm{D}_{2} \mathrm{O}, \mathrm{pH} 6,25^{\circ} \mathrm{C}$ ) containing the signals of the methylene protons $\alpha$ to the amine nitrogen atom. While the signal of the ethyl group methylene protons is a first-order quartet, both signals of the ethylene and propylene segment methylene protons are higher-order multiplets due to magnetic inequivalence.

The other straight-chain derivatives, 6-TFA (n-propyl), 7-TFA ( $n$-butyl), and $8\left(-\mathrm{CH}_{2} \mathrm{CF}_{3}\right)$, also all showed chemically equivalent methylene proton pairs, though magnetic inequiva- 
lence was also in evidence in all cases for practically all methylenes $\alpha$ to the amine nitrogen atom and, in many cases, also apparent on the methylenes $\beta$ to the amine nitrogen atom. Similarly, a reduction of strong effects due to magnetic inequivalence, and thus providing multiplets more resembling first-order ones, was attained upon raising the temperature, with the cross over temperatures typically in the range of $45-55{ }^{\circ} \mathrm{C}$ for most multiplets (Table S1). Attributing magnetic inequivalence as the cause of the appearance of the signals, which could resemble two closely resonating signals in some cases, was supported by measurement of homodecoupling and 2D J-resolved spectra (Figures S2-S5), both of which revealed only one resonating signal for each multiplet signal. The cyclopropyl derivative, 9.TFA, in $\mathrm{D}_{2} \mathrm{O}$ at $25^{\circ} \mathrm{C}$ unfortunately only showed dynamic broadening for most of the signals and the dynamic broadening appeared to involve magnetic inequivalence in most cases in a similar manner to the straight-chain derivatives. Spectra recorded at higher temperatures, 45,55 , and $65^{\circ} \mathrm{C}$, displayed the reduced simplicities expected for many of the signals, though some signals were made more complex, or were broadened even more, due to an additional dynamic process(es). As a consequence, the nitrogen-inversion rate for 9.TFA could not be measured. Interestingly, even for some free bases, various chemically equivalent methylene protons also displayed strong effects due to magnetic inequivalence. Diffusion coefficients for these compounds 5-7 and 9 lay in the range 3.2-3.4 $\times 10^{-10} \mathrm{~m}^{2} \mathrm{~s}^{-1}$ in $\mathrm{D}_{2} \mathrm{O}$ at $25^{\circ} \mathrm{C}$ (Table S1).

The next three compounds examined, $\mathbf{1 1}, \mathbf{1 3}$, and $\mathbf{1 4} \cdot \mathbf{H C l}$, were all methyl esters rather than hydroxamic acids. Replacing the hydroxamic acid with a methyl ester eliminates the effects of any $-\mathrm{NHOH}$ interactions, such as intra- and intermolecular hydrogen bonding involving the hydroxamic group and restricted rotation about the amide-type bond. Consideration of the latter case, though, is of less concern as restricted rotation due to amide-type bonds should affect their $\alpha$ methylenes more, resulting in distinct species, while nitrogen inversions must affect their $\alpha$ methylenes more, and this is indeed what is observed with the cases examined thus far. Unfortunately, the methyl ester derivative with a - $\mathrm{CH}_{2} \mathrm{CF}_{3}$ group, 13 , like its hydroxamic acid counterpart 8 , also only exhibited magnetic inequivalence, which, also like 8 , was less evident at high temperatures. In DMSO- $d_{6}$, nitrogen inversion was fast and magnetic inequivalence was not apparent, though the signals could be broadened upon the addition of $\mathrm{HCl}$. The methyl ester derivative of $\mathbf{1}, \mathbf{1 4} \cdot \mathbf{H C l}$, and its homologous series partner 11, however, both exhibited similar behavior to the methyl parent compound 1.TFA (Table 1, Entries 7 and 8, respectively) with comparable nitrogen-inversion rates of 1.24 and $1.50 \mathrm{~s}^{-1}$, respectively, and diffusion coefficients at $25^{\circ} \mathrm{C}$. Increasing the temperature to $37^{\circ} \mathrm{C}$ for $\mathbf{1 4} \cdot \mathbf{H C l}$ (Table 1, Entry 9) only modestly increased the diffusion coefficient from 3.81 to $5.40 \times 10^{-10} \mathrm{~m}^{2} \mathrm{~s}^{-1}$, while the nitrogen-inversion rate increased from 1.24 to $5.32 \mathrm{~s}^{-1}$. Interestingly, a sample of $\mathbf{1 4} \cdot \mathbf{H C l}$ dissolved in $\mathrm{D}_{2} \mathrm{O}$, but not acidified ( $\mathrm{pH}$ 6, Table 1, Entry 10), still showed chemical inequivalence, though the rate could only be estimated due to the signals resonating closely to each other and partial overlap due to exchange broadening. In $\mathrm{D}_{2} \mathrm{O}-\mathrm{PBS}$ (1:1), the rate increased such that coalescence was passed, but some of the signals were still substantially exchanged broadened.

Next, compounds $\mathbf{1 0}$ and 12, the "reverse amide" structures (with the substituents of the amide group switched) of $\mathbf{1}$ and $\mathbf{1 4}$, respectively, were examined. Both compounds exhibited chemical inequivalence and comparable nitrogen-inversion rates were measured (Table 1, Entries 11 and 12, respectively). For 10, similar increases in the nitrogen-inversion rate and diffusion coefficient were obtained when the temperature was increased to $37^{\circ} \mathrm{C}$ (Table 1, Entry 13).

\subsection{Compound 15, the Epimeric Case}

The problem of nitrogen inversion causing reduced availability of the eutomer is potentially exasperated for interconverting epimers since the equilibrium could conceivably be heavily biased as the energies of the participating epimers are unequal, and, in the unfortunate case, the undesired stereoisomer could preferentially be favored in much the same way that other interconverting systems can be biased against the eutomer, e.g., 
amide-bond rotamers. Compound 15 (Figure 9) represents such a case, and examination of a sample of $\mathbf{1 5}$ as the free base only exhibited fast exchange for a concentrated solution ( $276 \mathrm{mM}$ concentration) in DMSO- $d_{6}$, though line broadening due to dynamic effects was still observable for a dilute solution ( $20 \mathrm{mM}$ concentration). A sample of $\mathbf{1 5} \cdot \mathbf{H C l}$ in $\mathrm{D}_{2} \mathrm{O}$ at $25^{\circ} \mathrm{C}$, however, showed considerable line broadening indicative of dynamic effects for a number of pyrrolidine ring signals in both the ${ }^{1} \mathrm{H}$ and ${ }^{13} \mathrm{C}$ NMR spectra with the proton methylene pair adjacent to the nitrogen atom extremely broad. The rate retardation was exacerbated in DMSO- $d_{6}$ solution, wherein line broadening was pronounced for all signals. The dynamics in effect may also include other processes such as ring inversion, possibly as a direct consequence of nitrogen inversion. For $15 \cdot \mathrm{HCl}$ in $\mathrm{D}_{2} \mathrm{O}$, a diffusion coefficient of $6.61 \times 10^{-10} \mathrm{~m}^{2} \mathrm{~s}^{-1}$ was measured (Table 1, Entry 14), thus the time required to traverse a distance of $2000 \AA$ is $0.030 \mathrm{~ms}$, while measurement of the exchange rate between the two interconverting epimers yielded a nitrogen-inversion rate of $1.19 \mathrm{~s}^{-1}$, i.e., $840 \mathrm{~ms}$ is the time required for nitrogen inversion.

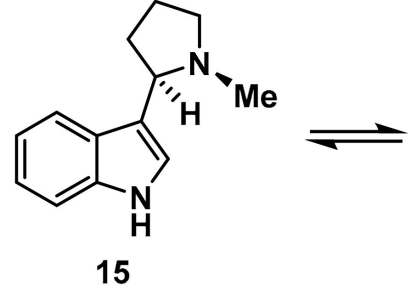

trans invertomer

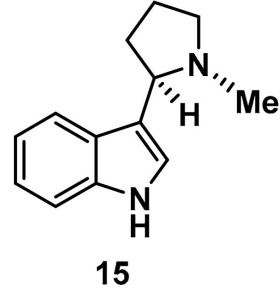

cis invertomer

Figure 9. Structures of the interconverting epimers of 15. The enantiomers of the two epimers are not shown but are present in the sample examined, i.e., the sample was racemic and all four stereoisomers are present.

\section{Conclusions and Summary}

The diffusion coefficients for compounds 1 and 3-15 lay in the range $3.2-4.5 \times 10^{-10} \mathrm{~m}^{2} \mathrm{~s}^{-1}$ in $\mathrm{D}_{2} \mathrm{O}$ at $25^{\circ} \mathrm{C}$ at low $\mathrm{pH}$, which increased to $4.9-5.4 \times 10^{-10} \mathrm{~m}^{2} \mathrm{~s}^{-1}$ at $37^{\circ} \mathrm{C}$, while measureable nitrogen-inversion rates lay in the range $1.2-5.5 \mathrm{~s}^{-1}$ at $25^{\circ} \mathrm{C}$. The nitrogeninversion rates more than doubled or quadrupled for two compounds at $37^{\circ} \mathrm{C}$, or increased considerably for all compounds upon deprotonation. A postulated intermediate range has been proposed that could affect binding of a ligand to a target protein. It is based on a capture-volume concept taking into account nitrogen inversion during the time a ligand takes to pass through a volume surrounding the protein binding site as calculated by the diffusion rate. The nitrogen-inversion rates measured here lie within this postulated intermediate range since they differ by a few orders of magnitude from the times required to traverse the capture volume. Thus, the availability, hence efficacy, of these compounds could potentially be affected if they were utilized as drugs. Intermediate nitrogen-inversion rates are therefore potentially significant for in silico drug design, drug efficacy, molecular modeling of drug-protein binding, pharmacokinetics, drug enantiomer evaluation, etc. since the possible reduction in drug availability relative to full availability for a molecule containing a single nitrogen-atom stereocenter ranges from 0.5 to 1 . Such reductions are treatment significant. Intermediate nitrogen-inversion rates are possibly of even greater concern for epimeric cases as the unequal energies of the interconverting species can lead to a heavy bias against the eutomer with the consequence that larger reductions in drug availability might occur. Since intermediate rates of nitrogen inversion can potentially affect protein binding, the process should therefore be taken into account during drug development and in vitro evaluation. The problem is likely to be general as there is nothing peculiar about this set of compounds and concerns extend to other compounds with intermediate nitrogen-inversion rates. 


\section{Materials and Methods}

NMR spectra were acquired using Bruker Avance 14.1 T and Avance III 9.4 T NMR spectrometers operating at 600 and $400 \mathrm{MHz}$, respectively, for ${ }^{1} \mathrm{H}$ nuclei and 150 and $100 \mathrm{MHz}$, respectively, for ${ }^{13} \mathrm{C}$ nuclei at the indicated temperatures. The experimental methodology used for measuring diffusion coefficients and longitudinal relaxation times (required for the calculation of nitrogen-inversion rates) has been described [32,33] previously, but briefly: Diffusion coefficients were measured without sample spinning using the bipolar pulse pair longitudinal eddy current delay (BPPLED) sequence [34] employing half-sinusoidal gradient pulses. The gradient strength was incremented linearly in 16 or 32 steps from $1.7-32.4$ or $0.8-40.5 \mathrm{G} / \mathrm{cm}$; the diffusion delay big delta, $\Delta$, was set to $20 \mathrm{~ms}$, little delta, $\delta$, to $4.4 \mathrm{~ms}$, the gradient pulses to $1.1 \mathrm{~ms}$, the eddy current delay, $T e$, to $5 \mathrm{~ms}$, and the $A q$ and post-acquisition delay (PAD) times together totaled 9.3 or $8.1 \mathrm{~s}$. The number of scans per gradient increment lay in the range 8-32. Longitudinal relaxation times were measured using demagnetization-recovery [35] with 16 or 32 recovery times within the range $0.001-25 \mathrm{~s}$. The number of scans per recovery time increment was 8 or 16. Numerical values for diffusion coefficients and longitudinal relaxation times were calculated based on area for both diffusion coefficient and longitudinal relaxation time measurements using curve-fitting procedures available in the Bruker software packages TopSpin 2.1 and 3.6. Nitrogen-inversion rates were measured using selective saturation transfer in conjunction with the aforementioned longitudinal relaxation times according to the following Equation (1):

$$
\text { inversion rate }=\left(I_{\text {sat }} / I_{0}-1\right) / T_{1,0},
$$

where $I_{\mathrm{sat}}$ and $I_{0}$ are the intensities of a signal with and without, respectively, signal saturation of its exchanging spin partner and $T_{1,0}$ is its longitudinal relaxation time without saturation transfer. Signal saturation was accomplished by the application of a soft rectangular pulse at low power for several seconds as required for total saturation. Standard applications of 1D homodecoupling, 2D COSY and EXSY for assignment purposes, and 2D $J$-resolved spectra with appropriate digital resolutions in the $\mathrm{f} 1$ and $\mathrm{f} 2$ dimensions were also utilized.

Samples of the amines 1-15 were supplied as either the free base or as the salt of hydrochloric acid or trifluoroacetic acid. Solutions of samples for NMR analysis were prepared in the indicated solvents and concentrations and, where needed, the $\mathrm{pH}$ of the solutions was lowered by the addition of concentrated $\mathrm{HCl}$. The syntheses of amines $\mathbf{1}$ and 3-15 are reported elsewhere [27,28].

Supplementary Materials: The following are available online at https://www.mdpi.com/article/ 10.3390/sym13091753/s1, Extended Table S1 of nitrogen-inversion rates and diffusion coefficients; further NMR spectra.

Author Contributions: Conceptualization, A.K.M., K.D.K.; methodology, R.R.S., G.T., M.N.E.G., K.D.K.; formal analysis, A.W., R.R.S., K.D.K., A.K.M.; investigation, R.R.S., K.D.K., A.K.M.; resources, A.K.M.; data curation, A.W., R.R.S., K.D.K., A.K.M.; writing—original draft preparation, K.D.K.; writing-review and editing, A.W., R.R.S., G.T., M.N.E.G., A.K.M., K.D.K.; supervision, A.K.M., K.D.K.; project administration, A.K.M. All authors have read and agreed to the published version of the manuscript.

Funding: This research received no external funding.

Institutional Review Board Statement: Not applicable.

Informed Consent Statement: Not applicable.

Data Availability Statement: The data presented in this study are available in this article and its associated Supplementary Materials.

Conflicts of Interest: The authors declare no conflict of interest. 


\section{References}

1. US Food and Drug Administration. FDA's Policy Statement for the Development of New Stereoisomeric Drugs. Chirality 1992, 4 , 338-340. [CrossRef] [PubMed]

2. Committee for Proprietary Medicinal Products. Note for Guidance: Investigation of Chiral Active Substances; Document III/3501/91-EN, draft 13. 1993. Available online: https:/ / docplayer.net/57670332-Investigation-of-chiral-active-substances.html (accessed on 11 June 2021).

3. Ballard, A.; Narduolo, S.; Ahmad, H.O.; Cosgrove, D.A.; Leach, A.G.; Buurma, N.J. The problem of racemization in drug discovery and tools to predict it. Expert Opin. Drug Discov. 2019, 14, 527-539. [CrossRef]

4. Landoni, M.F.; Soraci, A.L.; Delatour, P.; Lees, P. Enantioselective behaviour of drugs used in domestic animals: A review. J. Vet. Pharmacol. Therap. 1997, 20, 1-16. [CrossRef] [PubMed]

5. Cleeton, C.E.; Williams, N.H. Electromagnetic Waves of $1.1 \mathrm{~cm}$ Wave-Length and the Absorption Spectrum of Ammonia. Phys. Rev. 1934, 45, 234-237. [CrossRef]

6. Rauk, A.; Allen, L.C.; Mislow, K. Pyramidal Inversion. Angew. Chem. Int. Ed. 1970, 9, 400-414. [CrossRef]

7. Zawatzky, K.; Kamuf, M.; Trapp, O. Chiral 1,2-Dialkenyl Diaziridines: Synthesis, Enantioselective Separation, and Nitrogen Inversion Barriers. Chirality 2015, 27, 156-162. [CrossRef]

8. Rodríguez-Franco, M.I.; Dorronsoro, I.; Castro, A.; Martínez, A. Hindered Inversion/Rotation in Diheteroaryl Alkyl Amines with a N-(1-Pyrazolyl) Group: Dynamic NMR and Molecular Modelling Studies. Tetrahedron 2000, 56, 1739-1743. [CrossRef]

9. Bushweller, C.H.; Brown, J.H.; Harpp, K.S.; Hirth, B.H.; Barden, T.C.; D’Albis, J.N.; Gribble, G.W. Restricted Nitrogen Inversion in 9,10-Diazatetracyclo[6.3.0.0. ${ }^{411} 0.5,9$ ] undecanes. Dynamic NMR Studies. J. Org. Chem. 1998, 63, 3775-3777. [CrossRef]

10. Jaźwiński, J. Interaction of amines with rhodium(II) tetracarboxylates in solution: Formation of nitrogenous stereogenic center. Tetrahedron Asymmetry 2006, 17, 2358-2365. [CrossRef]

11. Tähtinen, P.; Sinkkonen, J.; Klika, K.D.; Nieminen, V.; Stájer, G.; Szakonyi, Z.; Fülöp, F.; Pihlaja, K. ${ }^{1} \mathrm{H},{ }^{13} \mathrm{C}$, and ${ }^{15} \mathrm{~N}$ NMR Stereochemical Study of cis-Fused 7a(8a)-Methyl and 6-Phenyl Octa(hexa)hydrocyclopenta[d][1,3]oxazines and [3,1]Benzoxazines. Chirality 2002, 14, 187-198. [CrossRef] [PubMed]

12. Tähtinen, P.; Bagno, A.; Klika, K.D.; Pihlaja, K. Modeling NMR Parameters by DFT Methods as an Aid to the Conformational Analysis of cis-Fused 7a(8a)-Methyl Octa(hexa)hydrocyclopenta[d][1,3]oxazines and [3,1]benzoxazines. J. Am. Chem. Soc. 2003, 125, 4609-4618. [CrossRef] [PubMed]

13. Rosling, A.; Klika, K.D.; Fülöp, F.; Sillanpää, R.; Mattinen, J. An NMR Conformational Study of Ring- and N-Inversion, and Prototropic Tautomerism in Stereoisomeric 2-[Arylamino(imino)]-4a,5,6,7,8,8a-hexahydro-(4H)-1,3,4-benzoxadiazines. Acta Chem. Scand. 1999, 53, 103-113. [CrossRef]

14. Rosling, A.; Hotokka, M.; Klika, K.D.; Fülöp, F.; Sillanpää, R.; Mattinen, J. The Conformational Behaviour of 4,4a,5,6,7,8Hexahydropyrido[1,2-d][1,3,4] ]oxadiazine Derivatives Studied by NMR Spectroscopy and Molecular Mechanics. Acta Chem. Scand. 1999, 53, 213-221. [CrossRef]

15. Rosling, A.; Klika, K.; Fülöp, F.; Sillanpää, R.; Mattinen, J. The Conformational Preference of Some Tetrahydropyrrolo[1,2d] [1,3,4] oxadiazine Derivatives as Studied by NMR Spectroscopy and X-ray Analysis. Heterocycles 1999, 51, $2575-2588$.

16. Viljanen, T.; Klika, K.D.; Fülöp, F.; Pihlaja, K. Coupling constants ${ }^{1} J\left({ }^{15} \mathrm{~N},{ }^{31} \mathrm{P}\right)$ as a probe for the conformational equilibria of 2-amino-substituted 1,3,2 $\lambda^{5}$-oxazaphosphinan-2-ones. J. Chem. Soc. Perkin Trans. 1998, 2, 1479-1481. [CrossRef]

17. Ertl, P.; Altmann, E.; McKenna, J.M. The Most Common Functional Groups in Bioactive Molecules and How Their Popularity Has Evolved over Time. J. Med. Chem. 2020, 63, 8408-8418. [CrossRef]

18. James, L.C.; Roversi, P.; Tawfik, D.S. Antibody Multispecificity Mediated by Conformational Diversity. Science 2003, 299, 1362-1367. [CrossRef]

19. Abe, I.; Kashiwagi, Y.; Noguchi, H.; Tanaka, T.; Ikeshiro, Y.; Kashiwada, Y. Ellagitannins and Hexahydroxydiphenoyl Esters as Inhibitors of Vertebrate Squalene Epoxidase. J. Nat. Prod. 2001, 64, 1010-1014. [CrossRef]

20. Fraga, C.G.; Oteiza, P.I. Dietary flavonoids: Role of (-)-epicatechin and related procyanidins in cell signaling. Free Radic. Biol. Med. 2011, 51, 813-823. [CrossRef] [PubMed]

21. Imberty, A.; Bourne, Y.; Cambillau, C.; Rougé, P.; Pérez, S. Oligosaccharide conformation in protein/carbohydrate complexes. Adv. Biophys. Chem. 1993, 3, 71-118.

22. Imberty, A. Oligosaccharide structures: Theory versus experiment. Curr. Opin. Struct. Biol. 1997, 7, 617-623. [CrossRef]

23. Diaz-Mauriño, T.; Solis, D.; Jeminéz-Barbero, J.J.; Martín-Lomas, M.; Siebert, H.-C.; Vliegenthart, J.F.G. Lectin meets ligand. Carbohydr. Eur. 1998, 23, 36-41.

24. Gilleron, M.; Siebert, H.-C.; Kaltner, H.; von der Lieth, C.-W.; Kozár, T.; Halkes, K.M.; Korchagina, E.Y.; Bovin, N.Y.; Gabius, H.-J.; Vliegenthart, J.F.G. Conformer selection and differential restriction of ligand mobility by plant lectin. Conformational behaviour of Gal $\beta 1-3 G l c N A c \beta 1-R$, Gal $\beta 1-3 G a l N A c \beta 1-R$ and Gal $\beta 1-2 \mathrm{Gal} \beta 1-\mathrm{R}^{\prime}$ in the free state and complexed with galactoside-specific mistletoe lectin as revealed by random-walk and conformational-clustering molecular-mechanics calculations, moleculardynamics simulations and nuclear Overhauser experiments. Eur. J. Biochem. 1998, 252, 416-427.

25. Von der Lieth, C.-W.; Kozár, T. Towards a better semiquantitative estimation of binding constants: Molecular dynamics exploration of the conformational behavior of isolated sialyllactose and sialyllactose complexed with influenza A hemagglutinin. J. Mol. Struct. 1996, 368, 213-222. [CrossRef] 
26. Von der Lieth, C.-W.; Kozár, T.; Hull, W.E. A (critical) survey of modelling protocols used to explore the conformational space of oligosaccharides. J. Mol. Struct. 1997, 395-396, 225-244. [CrossRef]

27. Géraldy, M.; Morgen, M.; Sehr, P.; Steimbach, R.R.; Moi, D.; Ridinger, J.; Oehme, I.; Witt, O.; Malz, M.; Nogueira, M.S.; et al. Selective Inhibition of Histone Deacetylase 10: Hydrogen Bonding to the Gatekeeper Residue is Implicated. J. Med. Chem. 2019, 62, 4426-4443. [CrossRef] [PubMed]

28. Steimbach, R.R.; Tihanyi, G.; Géraldy, M.N.E.; Herbst-Gervasoni, C.J.; Christianson, D.W.; Oehme, I.; Gunkel, N.; Miller, A.K. Rational Design Yields Selective Histone Deacetylase 10 Inhibitor. J. Med. Chem. 2021, submitted.

29. Zheng, G.; Stait-Gardner, T.; Anil Kumar, P.G.; Torres, A.M.; Price, W.S. PGSTE-WATERGATE: An STE-based PGSE NMR sequence with excellent solvent suppression. J. Magn. Reson. 2008, 191, 159-163. [CrossRef]

30. Price, W.S.; Elwinger, F.; Vigouroux, C.; Stilbs, P. PGSTE-WATERGATE, new tool for NMR diffusion-based studies of ligandmacromolecule binding. Magn. Reson. Chem. 2002, 40, 391-395. [CrossRef]

31. Veenstra, D.L.; Gerig, J.T. Fluorine NMR studies of the human carbonic anhydrase-3,5-difluorobenzenesulfonamide complex. Magn. Reson. Chem. 1998, 36, S169-S178. [CrossRef]

32. Kwiatkowska, M.; Wzorek, A.; Kolbus, A.; Urbaniak, M.; Han, J.; Soloshonok, V.A.; Klika, K.D. Flurbiprofen: A Study of the Behavior of the Scalemate by Chromatography, Sublimation, and NMR. Symmetry 2021, 13, 543. [CrossRef]

33. Baumann, A.; Wzorek, A.; Soloshonok, V.A.; Klika, K.D.; Miller, A.K. Potentially Mistaking Enantiomers for Different Compounds Due to the Self-Induced Diastereomeric Anisochronism (SIDA) Phenomenon. Symmetry 2020, 12, 1106. [CrossRef]

34. Wu, D.H.; Chen, A.D.; Johnson, C.S., Jr. An Improved Diffusion-Ordered Spectroscopy Experiment Incorporating BipolarGradient Pulses. J. Magn. Reson. Ser. A 1995, 115, 260-264. [CrossRef]

35. McDonald, G.G.; Leigh, J.S., Jr. A New Method for Measuring Longitudinal Relaxation Times. J. Magn. Reson. 1973, 9, 358-362. [CrossRef] 